\title{
Identification of blaVIM, blalMP and blaSPM-1 Metallo- $\beta$-Lactamase Genes in Bacillus subtilis Strains Isolated From Raw Milk and Cheese Samples
}

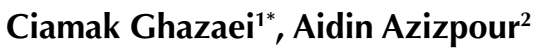 \\ 'Department of Microbiology, University of Mohaghegh Ardabili, Ardabil, Iran \\ ${ }^{2}$ Department of Animal Sciences, University of Mohaghegh Ardabili, Ardabil, Iran
}

\author{
*Correspondence to \\ Ciamak Ghazaei, Department \\ of Microbiology, University of \\ Mohaghegh Ardabili, Ardabil, Iran, \\ P.O. Box 179 . \\ Tel: +98 045-33512081-9, \\ Fax: +98 045-33510811, \\ Email: ciamakghazaei@yahoo.com
}

Received January 31, 2018 Accepted October 7, 2018 Published online December 31, 2018

\begin{abstract}
Introduction: Studies on bacterial resistance to common antibiotics are often based on bacteria isolated from patients, with less attention towards foodborne bacteria. This study aimed to investigate the antibiotic resistance pattern and the presence of metallo- $\beta$-lactamase $(\mathrm{MBL})$ genes viz blaVIM, blaIMP, and blaSPM-1, in the Bacillus subtilis strains isolated from raw milk and cheese samples.

Methods: A total of 100 raw milk and cheese samples (50 of each) were collected from the centers of production and distribution of dairy products in Ardabil city in 2017. Bacillus subtilis colonies susceptible to antibiotics were identified by conventional methods. Kirby-Bauer method was used to measure the antibiotic susceptibility and MBL E-test technique was used for detecting MBL enzymes. Presence of blaVIM, blaIMP, and blaSPM-1 MBL genes in the bacterial strains was investigated using PCR.

Results: The results showed that $25(59.52 \%)$ isolates from raw milk samples and $16(43.24 \%)$ isolates from cheese samples produced MBL enzyme. The MBL-producing isolates exhibited high level $(100 \%)$ of antibiotic resistance, except for cefixime $(67.40 \%)$ and cefotaxime $(64.60 \%)$. All MBL-producing isolates expressed blaVIM gene, while blaIMP and blaSPM-1 genes were not detected.

Conclusion: Based on our results, molecular detection of $\mathrm{MBL}$ genes can be used as a complementary method along with common phenotypic diagnostic methods in the samples of dairy products, tested positive for MBL.

Keywords: Bacillus subtilis, Metallo- $\beta$-lactamase, Enzymes, Antibiotic susceptibility, Cefotaxime
\end{abstract}

Please cite this article as follows: Ghazaei C, Azizpour A. dentification of blaVIM, blalMP and blaSPM-1 Metallo$\beta$-lactamase genes in Bacillus subtilis strains isolated from raw milk and cheese samples . Int J Basic Sci Med. 2018;3(4):188194. doi:10.15171/ ijbms.2018.32.

\section{Introduction}

Resistance of pathogenic bacteria to common antibiotics is an important barrier in treating infections caused by these microorganisms. The excessive use of antibiotics in the treatment of infectious diseases in humans and livestock has resulted in the increase of resistance to a wide range of antibiotics. ${ }^{1}$ Resistance to antibiotics is caused by mutation in either the bacterial genome or its plasmid. The plasmids have a major role in transferring the resistance from one bacterium to another. $^{2}$

According to the Ambler classification, beta-lactamase genes, responsible for a wide-spectrum of antibiotic resistance, are divided into 4 groups of A to D. From these, types $\mathrm{A}, \mathrm{C}$, and $\mathrm{D}$ produce $\beta$-lactamase, while type $B$ secretes metallo- $\beta$-lactamase (MBL). ${ }^{3}$ The MBL contains zinc ( $\mathrm{Zn}$ ) as the cofactor in its active site inhibited by the agents such as ethylenediaminetetraacetic acid (EDTA), sodium mercaptoacetic acid (SMA), 2-mercaptopropionic acid (MPA), and dipicolinic acid (DPA). One of the methods used for the laboratory diagnosis of MBL-producing bacterial strains is the utilization of specific inhibitors. Among the inhibitors of MBL, EDTA offers some advantages including being non-toxic and being easily available. As well, EDTAcontaining discs can be kept up to 16 weeks at $-20^{\circ} \mathrm{C} .{ }^{4}$ E-test strip could be used as another method for identifying MBLproducing bacteria; however, this is a costly

(c) 2018 The Author(s); Published by Zabol University of Medical Sciences. This is an open-access article distributed under the terms of the Creative Commons Attribution License (http://creativecommons.org/licenses/by/4.0), which permits unrestricted use, distribution, and reproduction in any medium, provided the original work is properly cited. 
method and renders lower validity. ${ }^{5,6}$

$\mathrm{MBL}$ is resistant to $\beta$-lactamase inhibitors such as sulbactam, tazobactam, and clavulanic acid. ${ }^{3}$ This resistance poses a major clinical problem since MBL can potentially influence various antibiotics including penicillin, broad-spectrum cephalosporins, and carbapenems (except for monobactam such as aztreonam). Carbapenems such as imipenem and meropenem are the most important antibiotics which can be used as antibacterial agents for treating infections caused by pathogens. ${ }^{6}$ Unfortunately, resistance towards these antibiotics is increasing. For example, Centers for Disease Control and Prevention (CDC) in the United States has announced that the resistance rate of $9 \%$ among isolated bacterial samples in 1995 has increased considerably to $40 \%$ in $2004 .^{7}$ IMP-1 in Serratia marcescens was identified as the first MBL enzyme in 1991. ${ }^{8}$ Over the past decade, MBLs have been categorized based on their molecular structures into 6 groups of GIM (German imipenemase), IMP (Imipenemase), SPM (São Paulo metallo- $\beta$-lactamase), SIM (Seoul imipenemase), VIM (Verona integron-encoded metallo- $\beta$-lactamase), and AIM (Adelaide imipenemase). ${ }^{9}$ Recently, a new type, KHM (Kyorin Health Science MBL), has been reported in Citrobacter freundii from Japan. ${ }^{10}$ The genes encoding MBLs are present on both chromosomes as well as plasmids. The MBL-encoding genes including blaVIM, blaIMP, and blaSPM-1 are found as a genetic cassette in class I integrins and have the potential for being transferred to other bacteria. ${ }^{4}$

Bacillus subtilis is a gram-positive and cylindricalshaped bacterium which is mostly found in soil and usually does not cause disease in humans. Characteristically, it forms large, flat, cloudy pale, yellow or brown colonies. ${ }^{11,12}$ In comparison with gram-negative bacteria, such as Escherichia coli, B. subtilis is considered GRAS (generally recognized as safe) according to a classification of the Food and Drug Administration (FDA), since it is generally found to be harmless towards mammals. For this reason, even today this bacterium is considered as a good host for the production of secretory heterologous proteins. ${ }^{13}$ With the active and efficient secretion system, this bacterium is capable of secreting various proteins into the peripheral environment, and is a suitable bacterium for cell growth and differentiation studies. These properties render the facilitation of production of recombinant proteins. ${ }^{14}$

To provide a generalized overview of MBL producers, Pseudomonas aeruginosa could be proposed as another interesting example along with $B$. subtilis. In a study by Doosti et $\mathrm{al}^{15}$ in Zanjan in 2011, out of 70 isolates of $P$. aeruginosa obtained from intensive care units (ICUs), 78\% were MBL producers. ${ }^{15}$ Based on molecular epidemiology studies on $P$. aeruginosa strains as MBL producers around the world, they were mostly prevalent in Netherlands, Greece, Italy, Japan, and Canada, and the most prevalent type was VIM. ${ }^{4}$ In another study by Yousefi et al in 2010, 39 out of 104 isolates of $P$. aeruginosa were reported as MBL positive strains, though in none of them, blaSPM-1 gene was detected in polymerase chain reaction (PCR) analysis. ${ }^{16}$

Microbial resistance has been extensively studied in bacteria isolated from disease cases. This is while few studies have been conducted on antibiotic resistance genes in foodborne bacteria. Therefore, our study was designed to survey the antibiotic resistance profile and genotype of B. subtilis strains isolated from samples of raw milk and cheese, along with detection of MBL encoding genes, blaVIM, blaIMP, and blaSPM-1 in these strains. Further effort should be directed to understand the probability of transferring resistance from these foodborne strains to other strains. The current study also provided an overview of the current state-of-art of the topic.

\section{Materials and Methods}

Sample Collection and Processing

At first a total of 100 samples of raw milk and cheese (50 samples of each) were collected in aseptic conditions from the Dairy Products Preparation and Distribution centers in Ardabil city, northwest province of Iran. First of all, the samples were treated with thermal enrichment for 10 minutes at $80^{\circ} \mathrm{C}$ to maintain spores and remove vegetative cells. Then, using serial dilution method, successive dilutions of the samples were prepared in sterile distilled water. Afterwards, $1 \mathrm{~mL}$ of each suspension was dispensed in sterile plates. Nutrient agar culture medium was then prepared and added to the petri dish under sterile conditions and incubated at $37^{\circ} \mathrm{C}$ for 24 hours. White and creamy colonies with rough and marginal surfaces were selectively purified through four-way streaking technique on nutrient agar-coated plate.

\section{Isolation and Identification of Bacillus subtilis}

To isolate B. subtilis strains, gram and malachite green stains were used in addition to biochemical tests (i.e. hydrolysis of lecithin, catalase test, indole test, tests with methyl red, citrate, and cell wall hydrolysates were used for glucose, arabinose, mannitol and xylose test. ${ }^{17}$

To investigate the proteolytic activity, bacteria were cultured on $50 \%$ skim milk agar medium and incubated at $37^{\circ} \mathrm{C}$ for $24-48$ hours. The presence of a bright area around the colony in the culture medium indicated bacterial proteolysis. The lipolytic activity of the strains was investigated by growing the bacteria in tributyrin agar culture medium at $37^{\circ} \mathrm{C}$ for 3 days. Finally, the growth inhibition zone around the colony was investigated. ${ }^{18}$

Determination of Antibiotic Resistance Pattern

To determine the antibiotic resistance, disk diffusion test was used in accordance with Kirby-Bauer method (Standard method for disk diffusion in agar), based on the 
CLSI protocol. ${ }^{19}$ The results were recorded after 18 hours by indicating the diameter of growth inhibition zone. The antibiotic disks (Mast Company, England) applied for resistance determination were cotrimoxazole $(25 \mu \mathrm{g})$, erythromycin $(15 \mu \mathrm{g})$, cefotaxime $(30 \mu \mathrm{g})$, gentamycin $(10 \mu \mathrm{g})$, augmentin $(30 \mu \mathrm{g})$, chloramphenicol $(30 \mu \mathrm{g})$, streptomycin $(10 \mu \mathrm{g})$, tetracyclin $(30 \mu \mathrm{g})$, piperacillin $(100$ $\mu \mathrm{g})$, and cefixime $(30 \mu \mathrm{g})$.

For each strain, the turbidity equivalent to $0.5 \mathrm{mg}$ MacFarland tube $\left(1.5 \times 10^{8}\right.$ bacteria $)$ of the bacterial suspension was prepared and streaked using a sterile swab on a solid culture medium (Mueller-Hinton agar). Using sterile forceps, the antibiotic discs were placed on the culture medium. The plates were incubated at $35^{\circ} \mathrm{C}$ for 18 to 24 hours. Inhibition zones were measured in millimeters and the bacterial susceptibility to antibiotic was reported. The measurements of the diameter of inhibition zone for antibiotics and their comparison were made according to the Clinical and Laboratory Standards Institute (CLSI) guidelines, and the strains were considered as either susceptible (S) or resistant (R).

Detection of MBLs Using Double-Sided E-Test Strip MBL enzymes were characterized by the phenotypic method using double-sided E-test strip (Imipenem and Imipenem + EDTA) purchased from Bio Merieux (SA, France).$^{20}$ One side of the strip contained varying concentrations of imipenem $(0.125$ to $8 \mu \mathrm{g} / \mathrm{mL})$ and the other side contained varying concentrations of imipenem + EDTA (0.032 to $2 \mu \mathrm{g} / \mathrm{mL})$. In the next step, a turbidity equivalent to $0.5 \mathrm{McF}$ arland tube of the bacterial suspension was inoculated in Muller-Hinton agar medium, on which the E-test strip was placed. The plates were then incubated at $35^{\circ} \mathrm{C}$ for 24 hours. To determine the presence of $\mathrm{MBL}$ enzymes, the intersection point of the halo formed on both sides of the strip (imipenem and imipenem + EDTA) was considered as an inhibitory concentration (IC) and was quantitatively reported as microgram per milliliter. According to the manufacturer's instructions, if imipenem + EDTA inhibitory dilution was reduced by more than three dilutions in comparison to imipenem, or the proportion of imipenem inhibitory dilution was greater than or equal to 8 , the strain was considered to be an MBL producer. ${ }^{21}$

Studies have shown that the accuracy of the E-test in evaluating MBL activity is higher than that of other conventional methods. ${ }^{5}$ In the E-test method, one side of a plastic strip is used to increase the concentration of an antimicrobial agent while the other side has a continuous minimum inhibitory concentration (MIC) grading. Thus, an effective antibiotic gradient is warranted against the bacteria. If the isolate is susceptible towards the antibiotic, growth inhibition zone is seen as an oval area on the agar plate. The peak of the strip that breaks the oval growth inhibition zone denotes the MIC. In the strips, imipenem is placed on one half of the gradient strip, while imipenem + EDTA is placed on the other half of the gradient (Figure 1). In cases where the imipenem MIC is greater than 8 , or is equal to the imipenem + EDTA, the production of MBL enzyme is detected. ${ }^{13,22}$

\section{Molecular Confirmation of MBLs}

The bacterial DNA was extracted using boiling method for PCR. Firstly, 3 to 5 fresh bacterial colonies were removed from the culture medium and dissolved in $200 \mu \mathrm{L}$ sterile distilled water and boiled for 10 minutes at $100^{\circ} \mathrm{C}$. This was followed by centrifugation at 12000 rpm for about 10 minutes. The supernatant containing DNA was used for PCR analysis. ${ }^{23}$ The PCR reaction was performed in thermocycler as follows: initial denaturation at $94^{\circ} \mathrm{C}$ for 5 minutes; 30 cycles of amplification including denaturation at $94^{\circ} \mathrm{C}$ for 1 minute, annealing at $56^{\circ} \mathrm{C}$ for 30 seconds, and extension at $72^{\circ} \mathrm{C}$ for 30 seconds; and final extension at $72^{\circ} \mathrm{C}$ for 5 minutes. ${ }^{24}$ The PCR test was performed to identify blaVIM (382 bp), blaIMP (587 bp), and blaSPM-1 (650 bp) genes using VIM, IMP and SPM-1 primers, respectively (Table 1 ).

\section{Results}

Our results showed that from a total of 100 isolates obtained from raw milk samples (non-pasteurized: 50 isolates) and cheese samples (50 isolates), 42 (84\%) isolates out of raw milk and 37 (74\%) isolates out of cheese samples contained B. subtilis. Upon biochemical analysis of MBL enzymes using phenotypic double-sided E-test strip, 25 (59.52\%) isolates of raw milk and 16 (43.24\%) isolates of cheese were able to produce MBL enzyme.

Totally, all MBL-producing isolates (100\%) exhibited

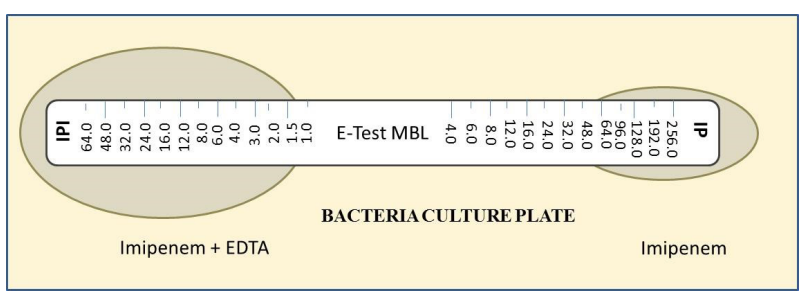

Figure 1. Representation of E-test Method With Imipenem on One Half of the Gradient Strip, and Imipenem + EDTA on the Other Half.

Table 1. Primers Applied in PCR Reaction

\begin{tabular}{lll}
\hline Gene & Primer & Gene Length \\
\hline VIM $F$ & $5^{\prime}$ - GTTTGGTCGCATATCGCAAC -3' & \\
VIM $R$ & 5'- AATGCGCAGCACCAGGATAG -3' & \\
IMP F & $5^{\prime}$ - ACCGCAGCAGAGCCTTTGCC -3' & \\
IMP $R$ & $5^{\prime}$ - ACAACCAGTTTTGCCTTACC -3' & \\
blaSPM-1 F & $5^{\prime}$ - CCTACAATCTAACGGCGACC -3' & \\
blaSPM-1 $R$ & $5^{\prime}$ - TCGCCGTGTCCAGGTATAAC -3' & \\
\hline
\end{tabular}

F; forward primer, $\mathrm{R}$; reverse primer. 
antibiotic resistance towards cotrimoxazole and cloxacillin, while the number of isolates showing resistance to the cefixime and cefotaxime were $67.40 \%$ and $64.60 \%$, respectively (Figure 2 ).

The resistance rate of $\mathrm{MBL}$ negative isolates to the antibiotics has been graphically represented in Figure 3. The highest antibiotic resistance was observed to cotrimoxazole $(68.29 \%)$, while the lowest value was recorded for cefixime (46.34\%).

The results of PCR reaction for blaVIM, blaIMP, and blaSPM-1 genes from $B$. subtilis strains isolated from raw milk and cheese samples are shown in Figure 4, Panel A. While all the strains revealed the presence of blaVIM gene, expressing MBL enzyme, none showed the presence of blaIMP and blaSPM-1 genes (Figure 4, Panel B).

\section{Discussion}

Milk and dairy products play a significant role in human nutrition because of their high nutritional value. However, due to the presence of most of the elements and nutrients, it is a very good environment for the growth and activity of many pathogenic microorganisms. Thus, non-compliance with the principles of hygiene in the preparation and maintenance of dairy products poses many health problems and dangers to consumers of such foodstuffs. The consumption of raw milk, unpasteurized or uncooked

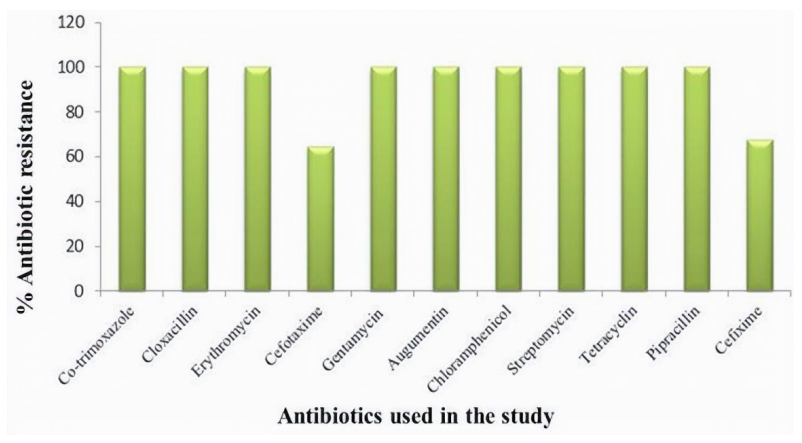

Figure 2. The Susceptibility of MBL Positive Isolates of Bacillus subtilis Towards Antibiotics by Disc Diffusion Method (The result has been expressed as \% of antibiotic resistance).

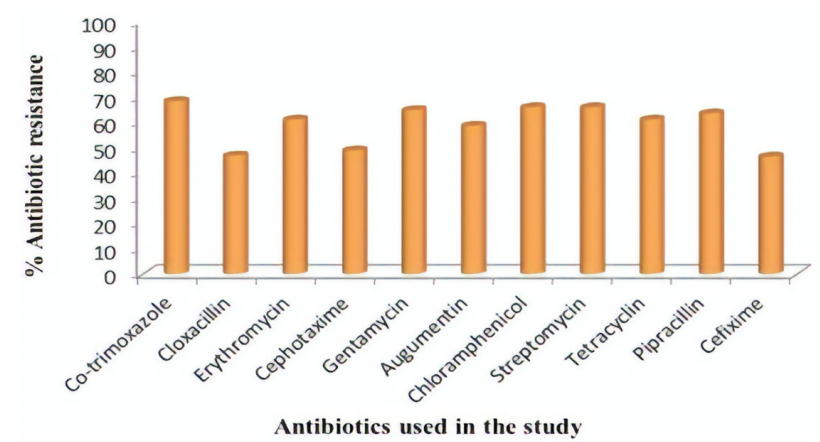

Figure 3. The Susceptibility of MBL Negative Isolates of Bacillus subtilis Towards Antibiotics by Disc Diffusion Method (The result has been expressed as \% of antibiotic resistance).

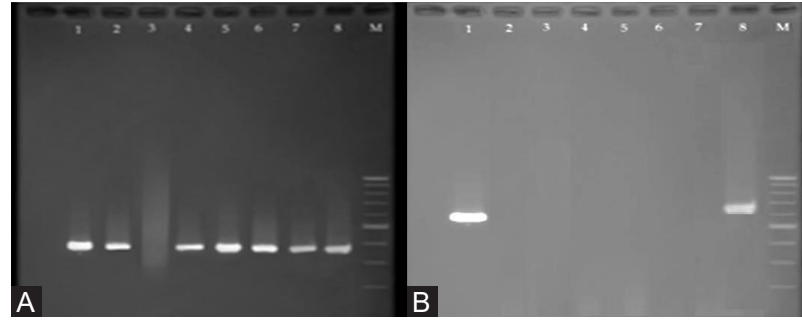

Figure 4. Gel Electrophoresis of PCR Products; A) blaVIM gene and B) blalMP and blaSPM-1 genes. In the panel A, lane 5 shows positive control for blaVIM, lanes 1, 2, 4, 6, 7, and 8 show positive samples for blaVIM, and lane 3 represents negative control. In the panel B, lanes 1 and 8 represent positive controls for blalMP and blaSPM-1, respectively. Samples (lanes 1, 2, 3, 4, 5, 6, and 7) express none of these genes. M; 100 bp DNA marker

contaminated dairy products or even pasteurized dairy products is one of the most common routes of transmitting diseases, along with several antibiotic-resistant bacteria. Production of beta-lactamases is the most common cause of antibiotic resistance in bacteria. ${ }^{25}$ Food contamination with antibiotic-resistant strains increases the risk of passing antibiotic resistance to the intestinal bacterial flora; hence, it should be considered as a significant risk factor. ${ }^{25,26}$ Researches have shown that a high percentage of raw milk samples are contaminated with bacillus, and warrants application of effective methods to eliminate such pathogens.

Based on the results of this study, B. subtilis isolates, producing the MBL enzyme, exhibited the highest (100\%) resistance towards cotrimoxazole and cloxacillin, while the resistance to cefotaxime $(64.60 \%)$ and cefixime (67.4\%) antibiotics was the lowest. MBL-driven resistance to carbapenems, as the most effective antibiotics against bacterial infections, is an issue of utmost concern. ${ }^{27}$ Carbapenems such as imipenem, meropenem, biapenem, and ertapenem are an important class of $\beta$-lactam drugs to which beta-lactamases are resistant. ${ }^{28}$ In a study by Magalhães et $\mathrm{al}^{29} 48$ samples of $P$. aeruginosa were collected, of which 24 (50\%) were imipenem-resistant, and $15(31.25 \%)$ samples were found to be producers of MBL enzymes. ${ }^{29}$ In a study by Franco et $\mathrm{al}^{24}$ on blood bacterial isolates, the prevalence of imipenem-resistant P. aeruginosa strains was reported to be $34 \%$, of which $77 \%$ were $\mathrm{MBL}$ producers. ${ }^{23}$ A similar and consistent observation was found in our study where $75 \%$ of milk samples and $75.42 \%$ of cheese samples were MBL producers.

In their study in 2008, Khosravi and Mihani showed that in all the strains they studied, the expression of blaVIM gene was observed. ${ }^{30}$ In the present study, PCR was used to confirm the presence of blaVIM, blaIMP, and blaSPM-1 MBL genes in B. subtilis strains isolated from raw milk and cheese samples. The results confirmed the presence of blaVIM gene in the same strains that produced the enzyme in the phenotypic test. While all the 
MBL-producing strains harbored blaVIM gene, no strains were found to carry either blaIMP or blaSPM-1 genes.

In a study by Varaiya et $\mathrm{al},{ }^{31}$ they reported the expression of blaIMP in neither of $20 \%$ imipenem-resistant strains. They also showed that $12.4 \%$ of the strains expressed blaVIM gene. The findings are consistent with our results in only showing the presence of blaVIM gene and the absence of blaIMP and blaSPM-1 genes in MBL producer B. subtilis. A study carried out by Franco et al on MBL producer blood isolates of $P$. aeruginosa, $34 \%$ of the strains were imipenem-resistant while $77 \%$ of the samples were MBL producers from which $81 \%$ contained the blaSPM-1 gene. ${ }^{24}$ Likewise, in a study performed by Sadeghi et $\mathrm{al}^{32}$ on 108 isolates of P. aeruginosa, the absence of blaSPM-1 gene was observed in all the strains. ${ }^{32}$ Torkar and Bedenic in their study on Bacillus cereus isolates (closely related strain to B. subtilis) obtained from clinical specimens and foods (raw and pasteurized milk) confirmed that $27.3 \%$ of strains expressed BlaVIM gene. ${ }^{33}$ However, $37 \%$ of strains that were positive in double disc diffusion method showed negative results in PCR analysis of blaSPM gene. They also detected MBL sequences encoding blaII (BCII) in all tested strains. ${ }^{33}$ In another study on 28 clinical isolates of P. aeruginosa, 15 isolates were found positive for blaVIM gene. ${ }^{34}$ Overall, the blaVIM gene is the most frequent gene in MBL producer bacterial strains and therefore the importance of this gene should not be neglected in nosocomial infections and even outbreaks. Moreover, Jovcic et al showed that $3 \%$ of imipenem-resistant isolates of $P$. aeruginosa expressed $M B L$ genes. ${ }^{35}$ In their study, Faghri et al found no expression of blaVIM-1 and blaSPM-1 in $P$. aeruginosa strains, highlighting the importance of other potential $M B L$-related genes than blaVIM-1 and blaSPM-1. ${ }^{36}$ In 2015, Mehdi et al isolated MBL-producing VIM-1, SPM-1, and IMP-1 genes from clinical Pseudomonas species. A total of $5.7 \%$ of the isolates showed resistance to imipenem. Furthermore, 9 (4.7\%) of the isolates were MBL producers, of which VIM1 was found by PCR test in 7 isolates. ${ }^{37}$ A study in 2017, carried out by Chika et al, was done for the molecular identification of MBL genes blaIMP-1 and blaSPM- $1 .{ }^{38}$ In $E$. coli isolates from cows, $31 \%$ were MBL producers with $8 \%$ expressing blaIMP-1 gene. ${ }^{38}$ This is while all of the isolates were negative for blaSPM-1 gene in the recent report. ${ }^{38}$

\section{Conclusion}

In this study, MBL producer B. subtilis strains were assessed in raw milk and cheese samples as key dairy products. It was shown that $100 \%$ of the MBL producer strains were resistant to the antibiotics cotrimoxazole and cloxacillin. The high occurrence of the $\beta$-lactamaseproducing microorganisms is a matter of concern for the medical and food industries. They are still known for the rapid infection and spread of nosocomial diseases.
Furthermore, their resistant nature makes them very difficult to eradicate. Thus, proper infection control measures and hygiene programs need to be implemented. According to our results, although it may not render a very sensitive approach, PCR can be used as a complementary method for detecting MBL genes in bacterial strains.

\section{Ethical Approval}

Not applicable.

\section{Competing Interests}

Authors declare no competing interests.

\section{Acknowledgment}

The authors would like to thank all the subjects who participated in the study.

\section{References}

1. Guajardo-Lara CE, González-Martínez PM, AyalaGaytán JJ. Antibiotic resistance of Escherichia coli from community-acquired urinary tract infections. What antimicrobial to use? Salud Publica Mex. 2009 51(2):155-159.

2. Unno $\mathrm{T}$, Han $\mathrm{D}$, Jang $\mathrm{J}$, et al. High diversity and abundance of antibiotic-resistant Escherichia coli isolated from humans and farm animal hosts in Jeonnam province, South Korea. Sci Total Environ. 2010 408(17):3499-3506. doi:10.1016/j.scitotenv.2010.04.046

3. Senda K, Arakawa Y, Ichiyama S, et al. PCR detection of metallo-beta-lactamase gene (blaIMP) in gramnegative rods resistant to broad-spectrum beta-lactams. J Clin Microbiol. 1996 34(12):2909-2913.

4. Pitout JDD, Gregson DB, Poirel L, McClure J-A, Le $\mathrm{P}$, Church DL. Detection of Pseudomonas aeruginosa producing metallo-beta-lactamases in a large centralized laboratory. J Clin Microbiol. 2005 43(7):3129-3135. doi:10.1128/JCM.43.7.3129-3135.2005

5. Walsh TR, Bolmström A, Qwärnström A, Gales A. Evaluation of a new Etest for detecting metallo-betalactamases in routine clinical testing. J Clin Microbiol. 2002 40(8):2755-2759.

6. Yan J-J, Wu J-J, Tsai S-H, Chuang C-L. Comparison of the double-disk, combined disk, and Etest methods for detecting metallo-beta-lactamases in gram-negative bacilli. Diagn Microbiol Infect Dis. 2004 49(1):5-11. doi:10.1016/j.diagmicrobio.2004.01.002

7. Naas T, Coignard B, Carbonne A, et al. VEB-1 ExtendedSpectrum $\beta$-lactamase-producing Acinetobacter baumannii, France. Emerg Infect Dis. 2006;12(8):12141222. doi:10.3201/eid1208.051547

8. Osano E, Arakawa Y, Wacharotayankun R, et al. Molecular characterization of an enterobacterial metallo beta-lactamase found in a clinical isolate of Serratia marcescens that shows imipenem resistance. Antimicrob Agents Chemother. 1994;38:71-78. doi:10.1128/AAC.38.1.71

9. Nordmann P, Poirel L. Emerging carbapenemases in Gram-negative aerobes. Clin Microbiol Infect. 2002 
8(6):321-331. doi: 10.1046/j.1469-0691.2002.00401.x

10. Sekiguchi J-i, Morita K, Kitao T, et al. KHM-1, a novel plasmid-mediated metallo-beta-lactamase from a Citrobacter freundii clinical isolate. Antimicrob Agents Chemother. 2008 52(11):4194-4197. doi:10.1128/ AAC.01337-07

11. Andrup L, Barfod KK, Jensen GB, Smidt L. Detection of large plasmids from the Bacillus cereus group. Plasmid. 2008 59(2):139-143. doi:10.1016/j.plasmid.2007.11.005

12. Kim K, Seo J, Wheeler K, et al. Rapid genotypic detection of Bacillus anthracis and the Bacillus cereus group by multiplex real-time PCR melting curve analysis. FEMS Immunol Med Microbiol. 2005 43(2):301-310. doi:10.1016/j.femsim.2004.10.005

13. Quale JM, Landman D, Bradford PA, et al. Molecular epidemiology of a citywide outbreak of extendedspectrum beta-lactamase-producing Klebsiella pneumoniae infection. Clin Infect Dis. 2002 35(7):834841. doi: $10.1086 / 342577$

14. Wong S-L. Advances in the use of Bacillus subtilis for the expression and secretion of heterologous proteins. Curr Opin Biotechnol. 1995 6(5):517-522. doi:10.1016/09581669(95)80085-9

15. Doosti M, Ramazani A, Garshasbi M. Identification and characterization of metallo- $\beta$-lactamases producing Pseudomonas aeruginosa clinical isolates in University Hospital from Zanjan Province, Iran. Iran Biomed J. 2013;17(3): 129-133. doi:10.6091/ibj.1107.2013

16. Yousefi S, Farajnia S, Nahaei MR, et al. Detection of metallo- $\beta$-lactamase-encoding genes among clinical isolates of Pseudomonas aeruginosa in northwest of Iran. Diagn Microbiol Infect Dis. 2010 68(3):322-325. doi:10.1016/j.diagmicrobio.2010.06.018

17. Massie J, Roberts G, White PJ. Selective isolation of Bacillus sphaericus from soil by use of acetate as the only major source of carbon. Appl Environ Microbiol. 1985 49(6):1478-1481.

18. Wehr HM, Frank JF. Standard Methods for the Examination of Dairy Products. American Public Health Association; 2004.

19. Clinical and Laboratory Standards Institute (CLSI). Performance Standards for Antimicrobial Susceptibility Testing; Twenty-First Informational Supplement. Wayne PA: CLSI; 2011.

20. Shivaprasad A, Antony B, Shenoy P. Comparative Evaluation of four phenotypic tests for detection of metallo- $\beta$-lactamase and carbapenemase production in Acinetobacter baumannii. J Clin Diagn Res. 2014 8(5):DC05-8. doi:10.7860/JCDR/2014/6447.4317

21. Tafti FA, Zandi H, Vakli M, Mousavi SM, Zarei M. Frequency of $\beta$-lactamase and metallo- $\beta$-lactamase in Pseudomonas aeruginosa strains isolated from burn wounds in Yazd burn hospital during 2011-2012. Feyz. 2014;18 (2):167-174.

22. Boschi L, Mercuri PS, Riccio ML, et al. The Legionella (Fluoribacter) gormanii metallo-beta-lactamase: a new member of the highly divergent lineage of molecularsubclass B3 beta-lactamases. Antimicrob Agents Chemother. 2000 44(6):1538-1543. doi:10.1128/ AAC.44.6.1538-1543.2000
23. Rodríguez-Baño J, Navarro $\mathrm{MD}$, Romero L, et al. Epidemiology and clinical features of infections caused by extended-spectrum beta-lactamaseproducing Escherichia coli in nonhospitalized patients. J Clin Microbiol. 2004 42(3):1089-1094. doi:10.1128/ JCM.42.3.1089-1094.2004

24. Franco MRG, Caiaffa-Filho HH, Burattini MN, RossiI F. Metallo-beta-lactamases among imipenem-resistant Pseudomonas aeruginosa in a Brazilian university hospital. Clinics (Sao Paulo). 2010;65(9):825-829. doi:10.1590/S1807-59322010000900002

25. Church D, Elsayed S, Reid O, Winston B, Lindsay R. Burn wound infections. Clin Microbiol Rev. 2006;19(2):403434. doi:10.1128/CMR.19.2.403-434.2006

26. Japoni A, Alborzi A, Kalani M, Nasiri J, Hayati M, Farshad S. Susceptibility patterns and cross-resistance of antibiotics against Pseudomonas aeruginosa isolated from burn patients in the South of Iran. Burns. 2006 32(3):343-347. doi:10.1016/j.burns.2005.10.017

27. Cornaglia G, Mazzariol A, Lauretti L, Rossolini GM, Fontana R. Hospital outbreak of carbapenem-resistant Pseudomonas aeruginosa producing VIM-1, a novel transferable metallo-beta-lactamase. Clin Infect Dis. 2000 31(5):1119-1125. doi:10.1086/317448

28. Luzzaro F, Endimiani A, Jean-DenisDocquier, et al. Prevalence and characterization of metallobeta-lactamases in clinical isolates of Pseudomonas aeruginosa. Diagn Microbiol Infect Dis.48(2):131-135.

29. Magalhães V, Lins AK, Magalhães M. Metallo-betalactamase producing Pseudomonas aeruginosa strains isolated in hospitals in Recife, PE, Brazil. Braz J Microbiol. 2005; 36(2):123-125. doi:10.1590/S151783822005000200005

30. Khosravi AD, Mihani F. Detection of metallo-betalactamase-producing Pseudomonas aeruginosa strains isolated from burn patients in Ahwaz, Iran. Diagn Microbiol Infect Dis. 2008 60(1):125-128. doi:10.1016/j. diagmicrobio.2007.08.003

31. Varaiya A, Kulkarni M, Bhalekar P, Dogra J. Incidence of metallo-beta-lactamase-producing Pseudomonas aeruginosa in diabetes and cancer patients. Indian J Pathol Microbiol.200851(2):200-203. doi:10.4103/03774929.41683

32. Sadeghi A, Rahimi B, Shojapour M. Molecular detection of metallo- $\beta$-lactamase genes blaVIM-1, blaVIM-2, blaIMP-1, blaIMP-2 and blaSPM-1 in Pseudomonas aeruginosa isolated from hospitalized patients in Markazi province by Duplex-PCR. Afr J Microbiol Res. 2012;6(12):2965-2969. doi:10.5897/AJMR11.1586

33. Torkar KG, Bedenić B. Antimicrobial susceptibility and characterization of metallo- $\beta$-lactamases, extendedspectrum $\beta$-lactamases, and carbapenemases of Bacillus cereus isolates. Microb Pathog. 2018 118:140-145. doi:10.1016/j.micpath.2018.03.026

34. Shahcheraghi F, Nikbin V, Shooraj F, Shafiei M. Investigation of blaIMP-1, blaVIM-1 and blaSPM-1 MBL genes among clinical strains of Pseudomonas aeruginosa isolated from Imam Khomeini hospital, Tehran, Iran. pajoohande. 2009;14(2):67-72.

35. Jovcic B, Vasiljevic Z, Djukic S, Topisirovic L, Kojic M. 
Emergence of VIM-2 metallo- $\beta$-lactamase-producing Pseudomonas aeruginosa isolates in a paediatric hospital in Serbia. J Med Microbiol. 2011 60:868-869. doi:10.1099/jmm.0.029173-0

36. Faghri J, Pourentezari M, Esmaeily M, Pirouzi S, Sedighi M. Prevalence of metallo-beta-lactamase genes blaVIM-1 and blaSPM-1 in Pseudomonas aeruginosa Clinical Isolates in Isfahan, Iran. Global J Medicine Res Stud. 2014; 1(1).

37. Ghamgosha M, Shahrekizahedani S, Kafilzadeh F,
Bameri Z, Taheri RA, Farnoosh G. Metallo-betalactamase VIM-1, SPM-1, and IMP-1 genes among clinical Pseudomonas aeruginosa species isolated in Zahedan. Iran Jundishapur J Microbiol. 2015 8(4):1-5. doi:10.5812/jjm.8(4)2015.17489

38. Chika E, Charles E, Ifeanyichukwu I, et al. Molecular Identification of MBL Genes blaIMP-1 and blaVIM-1 in Escherichia coli strains isolated from abattoir by multiplex PCR technique. Res J Microbiol. 2017;12(4):266-273. doi:10.3923/jm.2017.266.273 